\title{
Oestrogen plus progestin increased coronary heart disease and breast cancer in postmenopausal women
}

\author{
Writing Group for the Women's Health Initiative Investigators. Risks and benefits of estrogen plus progestin in healthy \\ postmenopausal women: principal results from the Women's Health Initiative randomized controlled trial.JAMA \\ 2002;288:321-33.
QUESTION: In postmenopausal women, what are the risks and benefits of oestrogen plus progestin use, particularly with respect to coronary heart disease (CHD) events?

\section{Design}

Randomised (allocation concealed), blinded (clinicians, participants, data collectors, outcome assessors, and monitoring committee), placebo controlled trial with a mean 5.2 years of follow up.

\section{Setting \\ 40 US clinical centres.}

\section{Patients}

16608 postmenopausal women who were $50-79$ years of age (mean age $63.3 \mathrm{y}$ ) with an intact uterus at baseline. Exclusion criteria included medical conditions associated with probable survival of $<3$ years, previous breast cancer or other cancer in the past 10 years (except nonmelanoma skin cancer), low hematocrit or platelet counts, and adherence and retention concerns (eg, alcoholism and dementia). Follow up was $96.5 \%$.

\section{Intervention}

Women were allocated to 1 daily tablet of conjugated equine oestrogen, $0.625 \mathrm{mg}$, and medroxyprogesterone acetate, $2.5 \mathrm{mg}$ (Prempro, Wyeth Ayerst, Philadelphia, PA, USA $)(n=8506)$, or placebo $(n=8102)$.

National Heart, Lun and Blood Institute and Wyeth-Ayerst

Research.

For correspondence: DrJ E Rossouw,

Division of Women's

Health Initiative,

National Heart, Lung, and Blood Institute,

Bethesda, MD, USA

rossouw@nih.gov

A modified version of this abstract appears in ACP Journal Club and Evidence-Based Medicine.

\section{Main outcome measures}

The primary outcomes were CHD (non-fatal myocardial infarction $[\mathrm{MI}]$ or $\mathrm{CHD}$ death) and invasive breast cancer. Other outcomes included stroke, venous thromboembolism (VTE) (deep venous thrombosis and pulmonary embolism [PE]), colorectal cancer, fractures, and death from other causes.

\section{Main results}

Analysis was by intention to treat. Because of early increases in breast cancer, follow up was stopped at a mean of 5.2 years instead of the expected 8.5 years. Women who received oestrogen plus progestin had a

Oestrogen plus progestin (Oest + Prog) v placebo for postmenopausal women*

\begin{tabular}{|c|c|c|c|c|}
\hline \multirow[b]{2}{*}{ Unfavourable outcomes } & \multicolumn{2}{|c|}{$\begin{array}{l}\text { Event rates per } \\
\text { patient-year }\end{array}$} & \multirow[b]{2}{*}{ RRI $(95 \% \mathrm{Cl})$} & \multirow[b]{2}{*}{ NNH (Cl) } \\
\hline & $\begin{array}{l}\text { Oest }+ \\
\text { Prog }\end{array}$ & Placebo & & \\
\hline All cardiovascular disease & $1.57 \%$ & $1.32 \%$ & $22 \%$ (9 to 36$)$ & 348 (213 to 848$)$ \\
\hline Coronary heart disease & $0.37 \%$ & $0.30 \%$ & $29 \%$ (2 to 63$)$ & 1152 (531 to 16693 ) \\
\hline Stroke & $0.29 \%$ & $0.21 \%$ & $41 \%$ (7 to 85$)$ & 1164 (562 to 6811$)$ \\
\hline Venous thromboembolism & $0.34 \%$ & $0.16 \%$ & $111 \%$ (58 to 182$)$ & 565 (345 to 1079) \\
\hline Invasive breast cancer & $0.38 \%$ & $0.30 \%$ & $26 \%$ (0 to 59$)$ & 1285 (567 to infinity) \\
\hline Favourable outcomes & & & RRR (CI) & NNT (Cl) \\
\hline Vertebral fracture & $0.09 \%$ & $0.15 \%$ & $34 \%$ (2 to 56$)$ & 1962 (1191 to 33358 ) \\
\hline Hip fracture & $0.10 \%$ & $0.15 \%$ & $34 \%$ (2 to 55$)$ & 1962 (1213 to 33358$)$ \\
\hline Colorectal cancer & $0.10 \%$ & $0.16 \%$ & $37 \%$ (8 to 57 ) & 1691 (1097 to 7819 ) \\
\hline
\end{tabular}

*Abbreviations defined in glossary; RRI, RRR, NNH, NNT, and $\mathrm{Cl}$ calculated from hazard ratios, $\mathrm{Cls}$, and control event rates in article. greater incidence of total cardiovascular disease than women who received placebo, including CHD (mainly non-fatal MI), stroke, and VTE (table). Invasive breast cancer was increased to a nearly statistically significant extent (table). Colorectal cancer and fractures were reduced (table). Groups did not differ for mortality.

\section{Conclusion}

In postmenopausal women, oestrogen plus progestin increased risk of cardiovascular disease, particularly coronary heart disease events.

\section{COMMENTARY}

Hormone replacement therapy (HRT) has been a controversial topic for patients and clinicians for decades. Unfortunately, the recently published results of the Women's Health Initiative (WHI) have served to further confound this perplexing issue. Product package inserts reveal that HRT is indicated for relief of menopausal symptoms and prevention of osteoporosis only. Despite these clear indications, long term use of HRT for prevention of chronic conditions such as heart disease has grown increasingly popular in many industrialised nations over the past half century. Indeed, the mean age of women in this study at baseline was 63.3 years. The results of the WHI confirm that long term treatment with combination HRT to prevent CHD is not appropriate.

The WHI is the first randomised primary prevention trial in postmenopausal women. It is a large trial with an ethnically diverse sample. The portion of the study that compared oestrogen plus progestin with placebo was the only arm terminated early because of an increase in adverse events. The oestrogen only arm of the study in women with hysterectomies was not discontinued, and we can assume that to date, oestrogen alone for these women may be safer than combination HRT.

The results of the WHI have mirrored previous studies regarding the increased risk of combination HRT in breast cancer incidence ${ }^{1}$ and increased cardiovascular events in the first year. ${ }^{23}$ The absolute risk of harm to an individual woman is small. For every 10000 women taking combination HRT for 1 year, there will be 7 more CHD events, 8 more invasive breast cancers, 8 more strokes, and 8 more pulmonary emboli, but 6 fewer colorectal cancers and 5 fewer hip fractures. Clinicians caring for perimenopausal and postmenopausal women must be able to summarise these results accurately for patients and together determine whether combination HRT should be used for short term relief of menopausal symptoms.

Cathy Kessenich, RN, DSN, ARNP Associate Professor University of Tampa, Tampa, Florida, USA

1 Colditz GA, Hankinson SE, Hunter DJ, et al. $N$ Engl J Med 1995;332:1589-93.

Hulley S, Grady D, Bush T, et al.JAMA 1998;280:605-13. Grady D, Herrington D, Bittner V, et al. JAMA 2002;288:49-57. 